\title{
Atomistic and Electronic Origin of Phase Instability of Metal Halide Perovskites
}

\author{
Junke Jiang¹, Feng Liu², Ionut Tranca ${ }^{3}$, Qing Shen², Shuxia Tao ${ }^{1 *}$.
}

${ }^{1}$ Center for Computational Energy Research, Department of Applied Physics, Eindhoven University of Technology, P.O. Box 5135600 MB Eindhoven, The Netherlands

2Faculty of Informatics and Engineering, The University of Electro-Communications, 1-5-1 Chofugaoka, Tokyo 182-8585, Japan

${ }^{3}$ Energy Technology, Department of Mechanical Engineering, Eindhoven University of Technology, P.O. Box 513, 5600 MB Eindhoven, The Netherlands.

Corresponding author

*E-mail: $\underline{\text { s.x.tao@tue.nl }}$ 


\section{Formation energy calculation of Sn vacancy}

We calculate the formation energies of Sn vacancy of $\mathrm{CsSn}_{\mathrm{y}} \mathrm{Pb}_{1-\mathrm{y}} \mathrm{I}_{3}$ perovskite $(\mathrm{y}=0.25,0.5$, and 0.75$)$. As references, we also calculate the same formation energy of pristine $\mathrm{CsSnI}_{3}$. The details of the computational procedure are as follows. The formation energy of Sn vacancy have been calculated by using a $2 \times 2 \times 1$ supercell, as given in eq 1 .

$$
\Delta E_{\text {vac }}\left[\mathrm{CsSn}_{\mathrm{y}} \mathrm{Pb}_{1-\mathrm{y}} \mathrm{I}_{3}\right]=E_{\text {tot }}\left[\mathrm{Sn}_{\mathrm{vac}}\right]-E_{\text {tot }}[\text { perovskite }]+\mu[\mathrm{Sn}]+E_{\mathrm{f}}
$$

where $E_{\text {tot }}\left[\mathrm{Sn}_{v a c}\right]$ and $E_{\text {tot }}$ [perovskite] are the total energies of the perovskite with and without Sn vacancy, respectively, and $\mu[\mathrm{Sn}]$ and $E_{\mathrm{f}}$ are the chemical potential of $\mathrm{Sn}$ and Fermi energy, respectively. The $\mu$ [ion] is assumed to be the same for all perovskites. This approximation is valid because in our experiments the important parameters (e.g., precursor concentration, the source of ions, and synthesis temperature) during synthesis process of these perovskites are kept the same. The $E_{\mathrm{f}}$ is assumed to be similar or with negligible difference for $\mathrm{CsSn}_{\mathrm{y}} \mathrm{Pb}_{1-\mathrm{y}} \mathrm{I}_{3}$ and $\mathrm{CsSnI}_{3}{ }^{1}$

We define the relative formation energy as Ref 2. The suppression of Sn vacancy formation by mixing $\mathrm{Sn}$ and $\mathrm{Pb}$ is quantitatively evaluated by eq 2 :

$$
\Delta \Delta E_{v a c}=\Delta E_{v a c}[\mathrm{Sn}-\mathrm{Pb}]-\Delta E_{v a c}[\mathrm{Sn}]
$$

Where $\Delta E_{\text {vac }}[\mathrm{Sn}-\mathrm{Pb}]$ is the formation energy of Sn vacancy in $\mathrm{Sn}$ and $\mathrm{Pb}$ mixed perovskite, and $\Delta E_{\text {vac }}$ $[\mathrm{Sn}]$ represents the one of the pure $\mathrm{CsSnI}_{3}$ perovskite. 
Table S1. Lattice constants (in $\AA$ ) of ten pure perovskite and non-perovskite phases considered in this work obtained by PBE functional compared to experimental data. a: ref 3, b: ref 4, c: ref. 5, d: ref. 6, e: ref. 7, f: ref. 8. Lattice parameter mismatch percentage (in \%) of this work compared with experimental values.

\begin{tabular}{|c|c|c|c|}
\hline Material & $\begin{array}{c}\text { Lattices constants } \\
\text { (this work) }\end{array}$ & $\begin{array}{c}\text { Lattice constants } \\
\text { (experimental) }\end{array}$ & $\begin{array}{c}\text { Lattice constant } \\
\text { mismatched percentage } \\
\text { (\%) }\end{array}$ \\
\hline$\alpha-\mathrm{FAPbI}_{3}$ & 6.47 & 6.357 a & 1.78 \\
\hline$\delta-\mathrm{FAPbI}_{3}$ & $8.72,8.72,7.95$ & $8.622,8.622,7.945 \mathrm{~b}$ & $1.14,1.14,0.06$ \\
\hline$\alpha-\mathrm{CsPb}_{3}$ & 6.38 & 6.2894 c & 1.44 \\
\hline$\delta-\mathrm{CsPbI}_{3}$ & $10.90,4.88,18.22$ & $10.462,4.799,17.765 \mathrm{~d}$ & $4.19,1.69,2.56$ \\
\hline$\gamma-\mathrm{CsSnI}_{3}$ & $8.99,12.52,8.63$ & $8.69,12.38,8.64 \mathrm{e}$ & $3.45,1.13,-0.12$ \\
\hline$\delta-\mathrm{CsSnI}_{3}$ & $10.94,4.82,17.99$ & $10.35,4.76,17.68 \mathrm{e}$ & $5.70,1.26,1.75$ \\
\hline$\alpha-\mathrm{CsSnBr}_{3}$ & 5.89 & $5.804 \mathrm{f}$ & 1.48 \\
\hline$\gamma-\mathrm{CsSnBr}_{3}$ & $8.36,11.79,8.22$ & - & - \\
\hline$\delta-\mathrm{CsSnBr}_{3}$ & $10.02,4.59,17.12$ & - & - \\
\hline
\end{tabular}

Table S2. Lattice constants (in $\AA$ ) of ten pure perovskite and non-perovskite phases considered in this work obtained by PBEsol functional compared to experimental data. a: ref 3, b: ref 4, c: ref. 5, d: ref. 6, e: ref. 7, f: ref. 8. Lattice parameter mismatch percentage (in \%) of this work compared with experimental values.

\begin{tabular}{|c|c|c|c|}
\hline Material & $\begin{array}{c}\text { Lattices constants } \\
\text { (this work) }\end{array}$ & $\begin{array}{c}\text { Lattice constants } \\
\text { (experimental) }\end{array}$ & $\begin{array}{c}\text { Lattice constant } \\
\text { mismatched percentage } \\
\text { (\%) }\end{array}$ \\
\hline$\alpha-\mathrm{FAPbI}_{3}$ & 6.37 & 6.357 a & 0.2 \\
\hline$\delta-\mathrm{FAPbI}_{3}$ & $8.66,8.66,7.90$ & $8.622,8.622,7.945 \mathrm{~b}$ & $0.44,0.44,-0.57$ \\
\hline$\alpha-\mathrm{CsPb}_{3}$ & 6.23 & 6.2894 c & -0.94 \\
\hline$\delta-\mathrm{CsPb}_{3}$ & $10.42,4.76,17.68$ & $10.462,4.799,17.765 \mathrm{~d}$ & $-0.40,-0.81,-0.48$ \\
\hline$\gamma-\mathrm{CsSnI}_{3}$ & $8.76,12.25,8.38$ & $8.69,12.38,8.64$ e & $0.81,-1.05,-3.01$ \\
\hline$\delta-\mathrm{CsSnI}_{3}$ & $10.40,4.69,17.59$ & $10.35,4.76,17.68 \mathrm{e}$ & $0.48,-1.47,-0.51$ \\
\hline$\alpha-\mathrm{CsSnBr}_{3}$ & 5.75 & 5.804 f & -0.93 \\
\hline$\gamma-\mathrm{CsSnBr}_{3}$ & $8.23,11.53,7.92$ & - & - \\
\hline$\delta-\mathrm{CsSnBr}_{3}$ & $9.67,4.47,16.62$ & - & - \\
\hline
\end{tabular}

Table S3. Lattice constants (in $\AA$ ) of ten pure perovskite and non-perovskite phases considered in this work obtained by SCAN-rVV10 functional compared to experimental data. a: ref 3, b: ref 4, c: ref. 5, d: ref. 6, e: ref. 7, f: ref. 8. Lattice parameter mismatch percentage (in \%) of this work compared with experimental values.

\begin{tabular}{|c|c|c|c|}
\hline Material & $\begin{array}{c}\text { Lattices constants } \\
\text { (this work) }\end{array}$ & $\begin{array}{c}\text { Lattice constants } \\
\text { (experimental) }\end{array}$ & $\begin{array}{c}\text { Lattice constant } \\
\text { mismatched percentage } \\
\text { (\%) }\end{array}$ \\
\hline$\alpha-\mathrm{FAPbI}_{3}$ & 6.26 & 6.357 a & -1.53 \\
\hline$\delta-\mathrm{FAPbI}_{3}$ & $8.66,8.66,7.90$ & $8.622,8.622,7.945^{\mathrm{b}}$ & $0.44,0.44,-0.57$ \\
\hline$\alpha-\mathrm{CsPb}_{3}$ & 6.05 & $6.2894^{\mathrm{c}}$ & -0.38 \\
\hline$\delta-\mathrm{CsPbI}_{3}$ & $10.03,4.61,17.15$ & $10.462,4.799,17.765^{\mathrm{d}}$ & $-4.13,-3.94,-3.46$ \\
\hline$\gamma-\mathrm{CsSnI}_{3}$ & $9.17,11.94,7.22$ & $8.69,12.38,8.64$ e & $5.52,-3.55,-16.44$ \\
\hline$\delta-\mathrm{CsSnI}_{3}$ & $10.00,4.52,17.20$ & $10.35,4.76,17.68 \mathrm{e}$ & $-3.38,-5.04,-2.71$ \\
\hline$\alpha-\mathrm{CsSnBr}_{3}$ & 5.60 & 5.804 f & -3.51 \\
\hline$\gamma-\mathrm{CsSnBr}_{3}$ & $8.65,11.29,6.78$ & - & - \\
\hline$\delta-\mathrm{CsSnBr}_{3}$ & $9.17,4.13,16.60$ & - & - \\
\hline
\end{tabular}


Table S4. The detailed synthetic recipes for obtaining various quantum dots (QDs) with compositions of $\mathrm{CsSn}_{1-\mathrm{y}} \mathrm{Pb}_{\mathrm{y}} \mathrm{I}_{3}(\mathrm{y}=0,0.25,0.5,0.75,1)$.

\begin{tabular}{|c|c|c|c|}
\hline QDs & TOP (mL) & $\mathrm{SnI}_{2}(\mathrm{mmol})$ & $\mathrm{PbI}_{2}(\mathrm{mmol})$ \\
\hline $\mathrm{CsPbI}_{3}$ & 2.5 & $/$ & 2 \\
\hline $\mathrm{CsSn}_{0.25} \mathrm{~Pb}_{0.75} \mathrm{I}_{3}$ & 2.5 & 2 & 0.9 \\
\hline $\mathrm{CsSn}_{0.5} \mathrm{~Pb}_{0.5} \mathrm{I}_{3}$ & 2.5 & 2 & 0.7 \\
\hline $\mathrm{CsSn}_{0.75} \mathrm{~Pb}_{0.25} \mathrm{I}_{3}$ & 2.5 & 2 & 0.45 \\
\hline $\mathrm{CsSnI}_{3}$ & 2.5 & 2 & $/$ \\
\hline
\end{tabular}
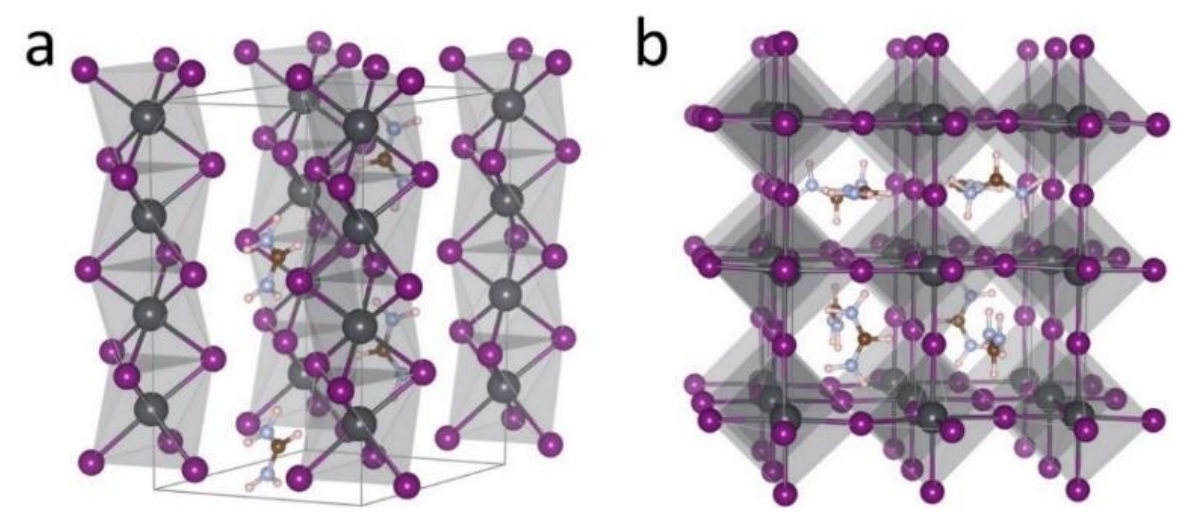

Figure S1. Structure models of (a) yellow $\delta$-phase $\mathrm{FAPbI}_{3}$ and (b) black $\alpha$-phase $\mathrm{FAPbI}_{3}$. The $1 \times 1 \times 2 \delta$ $\mathrm{FAPbI}_{3}$ and $2 \times 2 \times 2 \alpha-\mathrm{FAPbI}_{3}$ supercells are used for the calculations presented in the main text. It should be noted that, for $\mathrm{Cs}_{\mathrm{x}} \mathrm{FA}_{1-\mathrm{x}} \mathrm{PbI}_{3}$ perovskites, the non-perovskite structure of $\mathrm{FAPbI}_{3}$ and $\mathrm{CsPbI}_{3}$ are different. According to previous study, ${ }^{9-10}$ in the range of $0 \leq \mathrm{x} \leq 0.5$, the $\delta$ phase with hexagonal structure is adopted; for $0.5 \leq \mathrm{x} \leq 1$, the $\delta$-phase with orthorhombic structure is chosen. For $\mathrm{x}=0.5$, we calculate the energies of $\delta$-phase with both hexagonal and orthorhombic structures and adopt the one with the most negative energy. 

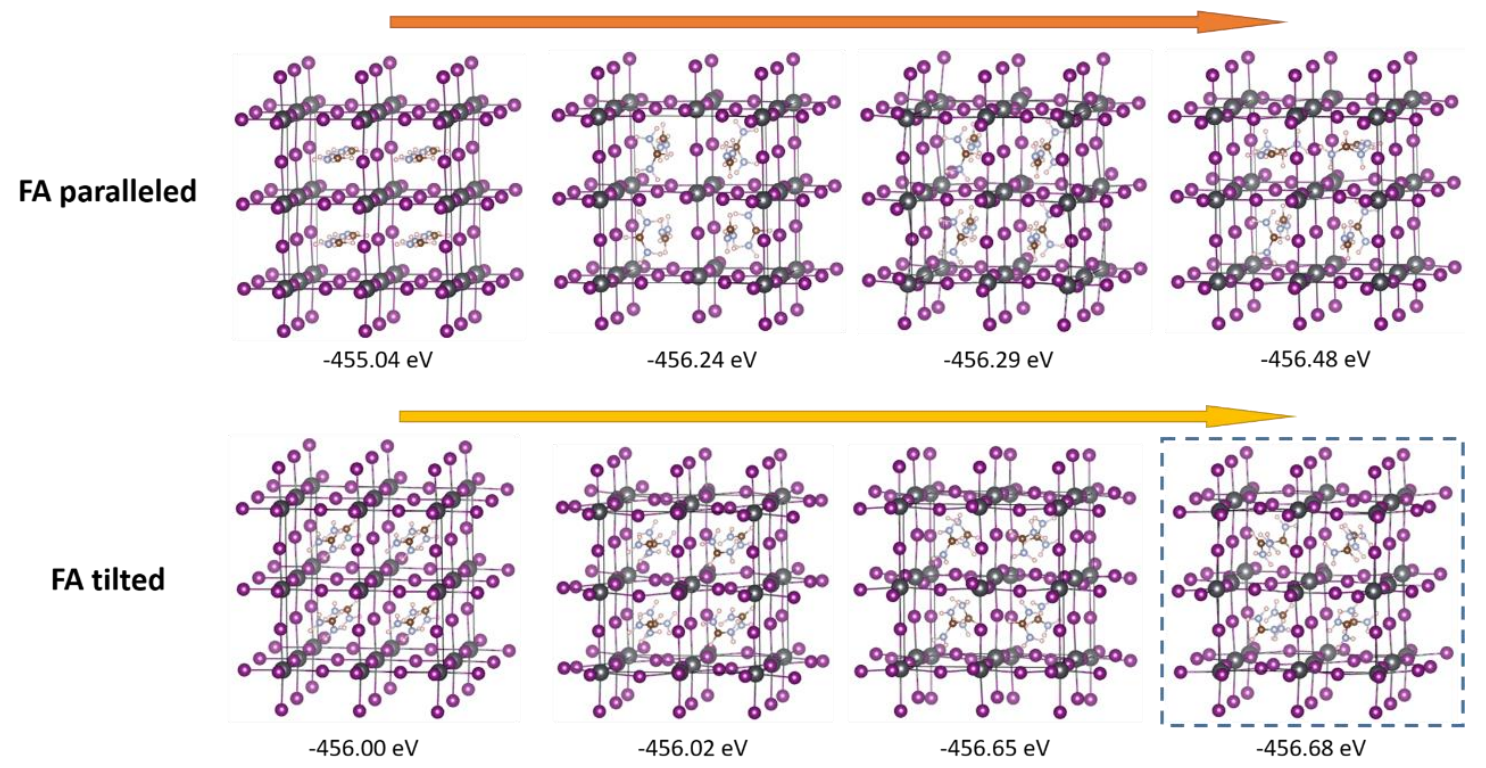

Figure S2. Structure models for $2 \times 2 \times 2 \alpha-\mathrm{FAPbI}_{3}$ with different FA orientations (paralleled and tilted) by increasing degree of disorder of FA. The configuration with the most disordered distribution of tilted FA cations is the most stable one, highlighted by blue dashed line.

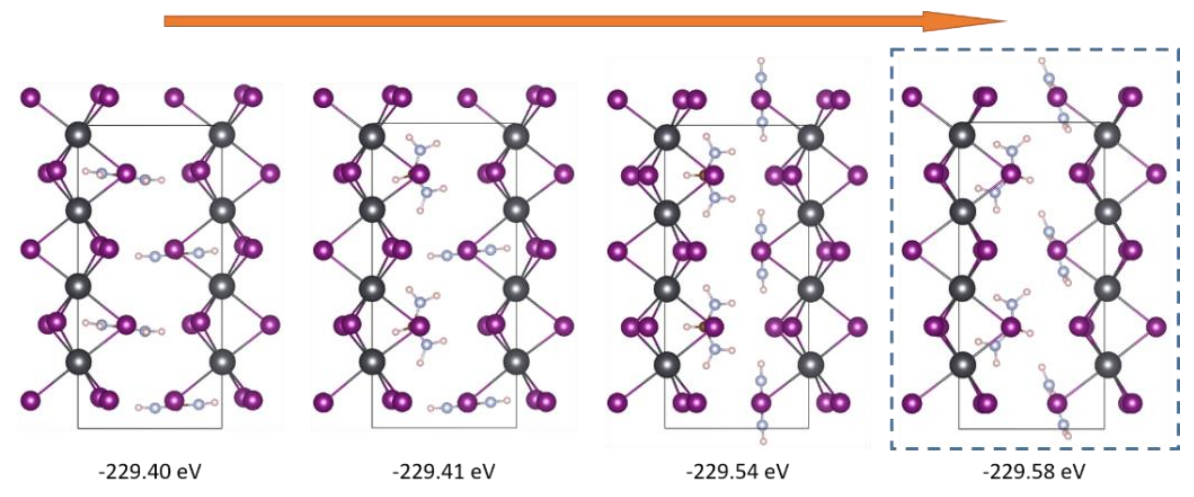

Figure S3. Structure models for $1 \times 1 \times 2$ hexagonal $\delta$-FAPbI 3 with different FA orientation by increasing degree of FA disorder. The configuration with the most disordered distribution of FA cations is the most stable one, highlighted by blue dashed line.

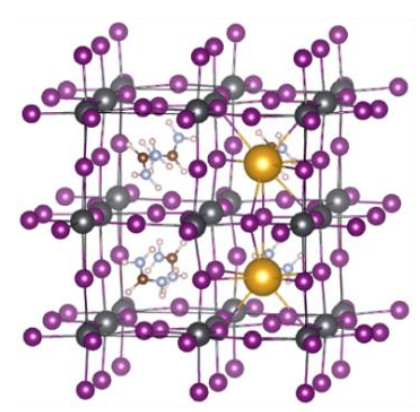

$-374.32 \mathrm{eV}$

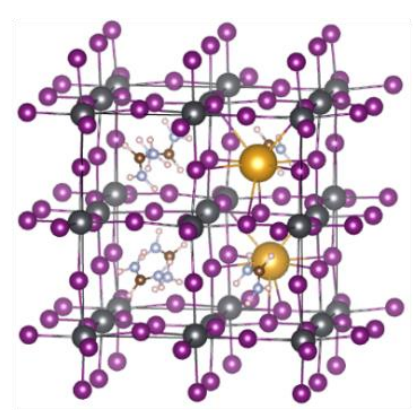

$-374.39 \mathrm{eV}$

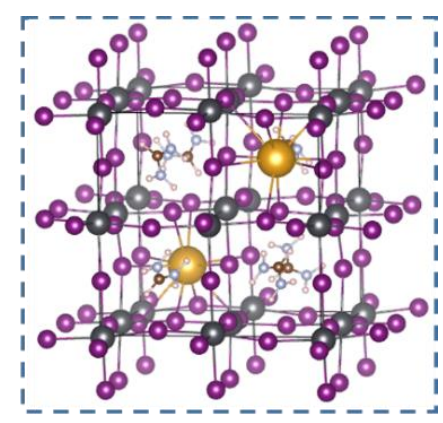

$-374.42 \mathrm{eV}$

Figure S4. Structure models for $2 \times 2 \times 2 \mathrm{Cs}_{0.25} \mathrm{FA}_{0.75} \mathrm{PbI}_{3}$ perovskite with different combination of Cs and FA cations. The most stable configuration is highlighted by blue dashed line. 

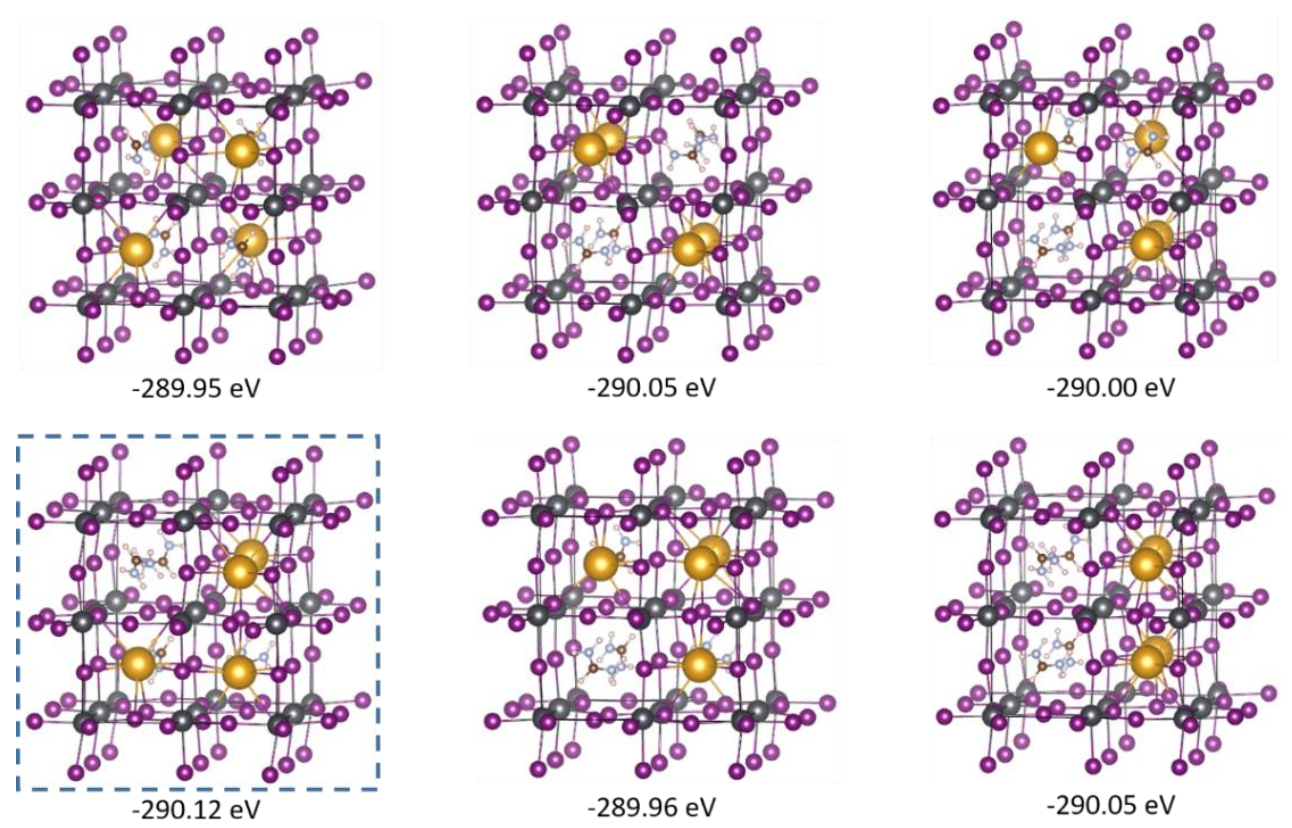

Figure S5. Structure models for $2 \times 2 \times 2 \mathrm{Cs}_{0.5} \mathrm{FA}_{0.5} \mathrm{PbI}_{3}$ perovskite with different combination of Cs and FA cations. The most stable configuration is highlighted by blue dashed line.
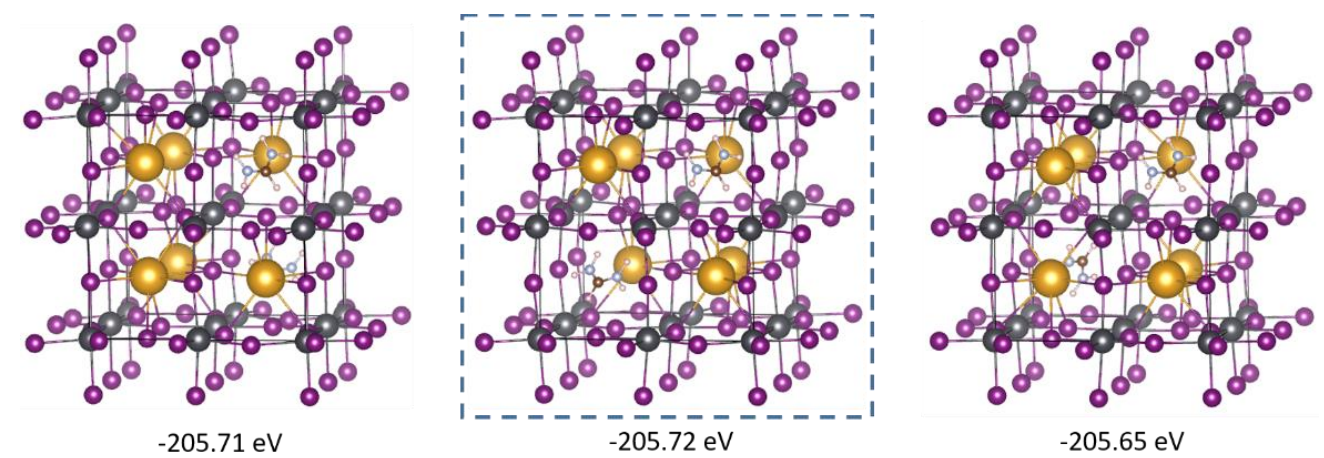

Figure S6. Structure models for $2 \times 2 \times 2 \mathrm{Cs}_{0.75} \mathrm{FA}_{0.25} \mathrm{PbI}_{3}$ perovskite with different combination of Cs and cations. The most stable configuration is highlighted by blue dashed line.

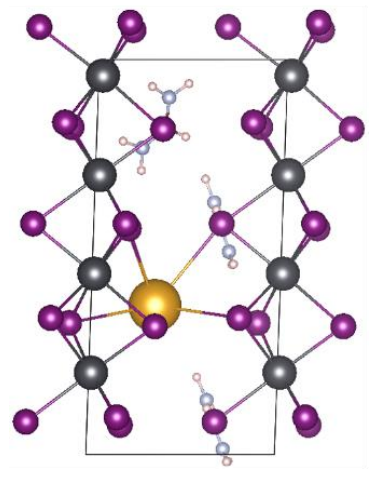

$-187.33 \mathrm{eV}$

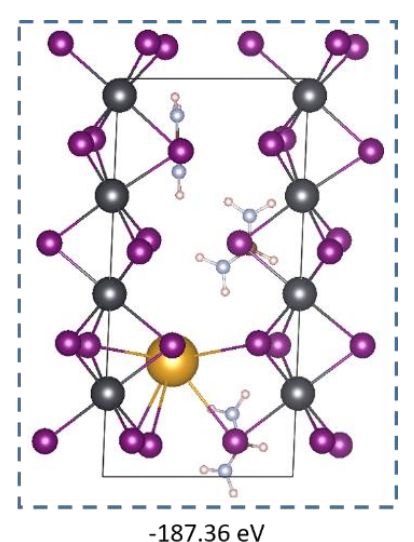

$-187.36 \mathrm{eV}$

Figure S7. Structure models for $1 \times 1 \times 2$ hexagonal $\mathrm{Cs}_{0.25} \mathrm{FA}_{0.75} \mathrm{PbI}_{3}$ non-perovskite with different combination of Cs and FA cations. The most stable configuration is highlighted by blue dashed line. 


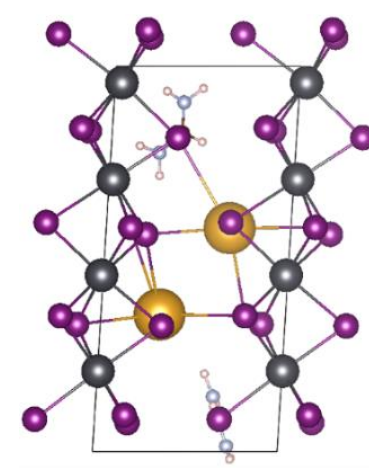

$-145.09 \mathrm{eV}$

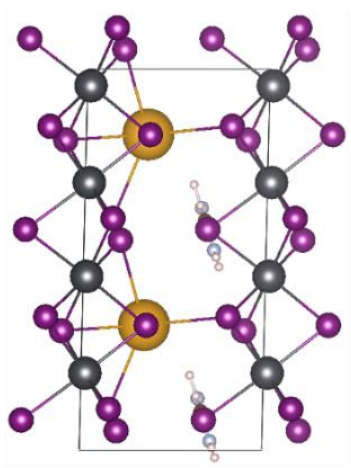

$-145.15 \mathrm{eV}$

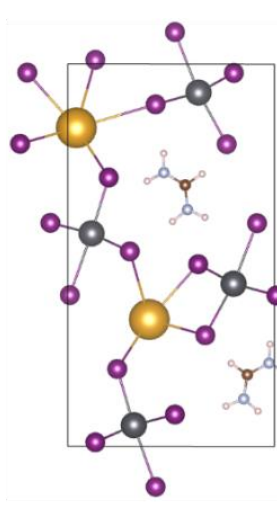

$-145.55 \mathrm{eV}$

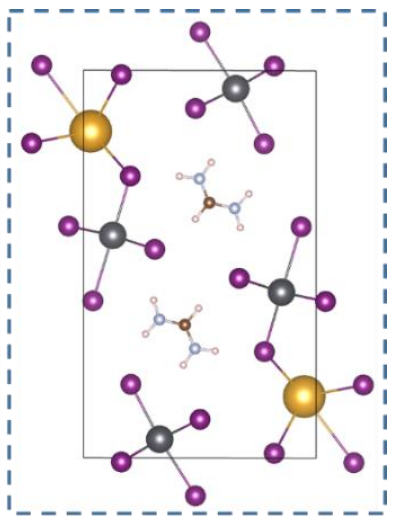

$-145.71 \mathrm{eV}$

Figure S8. Structure models for both $1 \times 1 \times 2$ hexagonal $\mathrm{Cs}_{0.5} \mathrm{FA}_{0.5} \mathrm{PbI}_{3}$ and $1 \times 1 \times 1$ orthorhombic $\mathrm{Cs}_{0.5} \mathrm{FA}_{0.5} \mathrm{PbI}_{3}$ non-perovskite with different combination of $\mathrm{Cs}$ and $\mathrm{FA}$ cations. The most stable configuration is highlighted by blue dashed line.
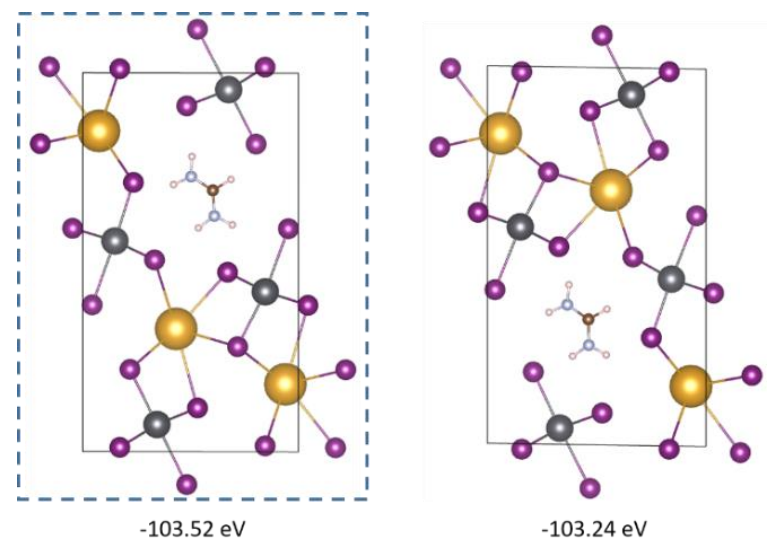

Figure S9. Structure models for $1 \times 1 \times 1$ orthorhombic $\mathrm{Cs}_{0.75} \mathrm{FA}_{0.25} \mathrm{PbI}_{3}$ non-perovskite with different combination of Cs and FA cations. The most stable configuration is highlighted by blue dashed line.

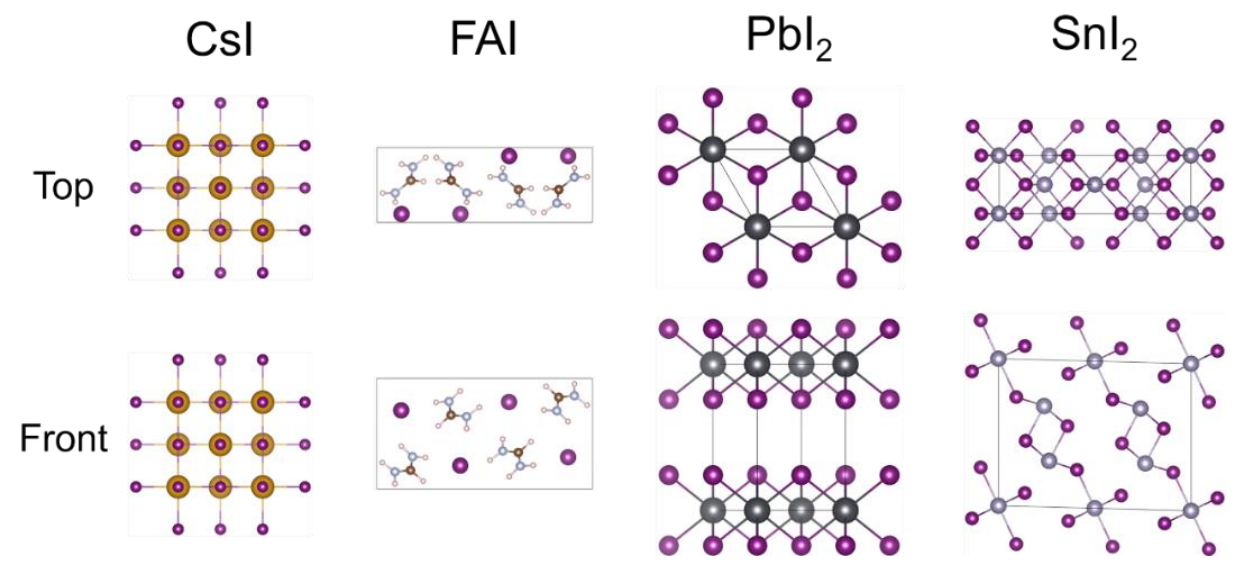

Figure S10. Structure models of CsI, FAI, $\mathrm{PbI}_{2}$, and $\mathrm{SnI}_{2}$. The CsI model consists of $4 \mathrm{Cs}$ atoms, and $4 \mathrm{I}$ atoms, respectively. The FAI model consists of $4 \mathrm{C}$ atoms, $8 \mathrm{~N}$ atoms, $20 \mathrm{H}$ atoms, and $4 \mathrm{I}$ atoms, respectively. The $\mathrm{PbI}_{2}$ model consists of $1 \mathrm{~Pb}$ atom and $2 \mathrm{I}$ atoms, respectively. The $\mathrm{SnI}_{2}$ model consists of $6 \mathrm{Sn}$ atoms and 12 I atoms, respectively. To calculate the formation energy of the perovskites, their energies are normalized by each formula unit ( $\mathrm{AM}$ or $\mathrm{MX}_{2}$ ). 


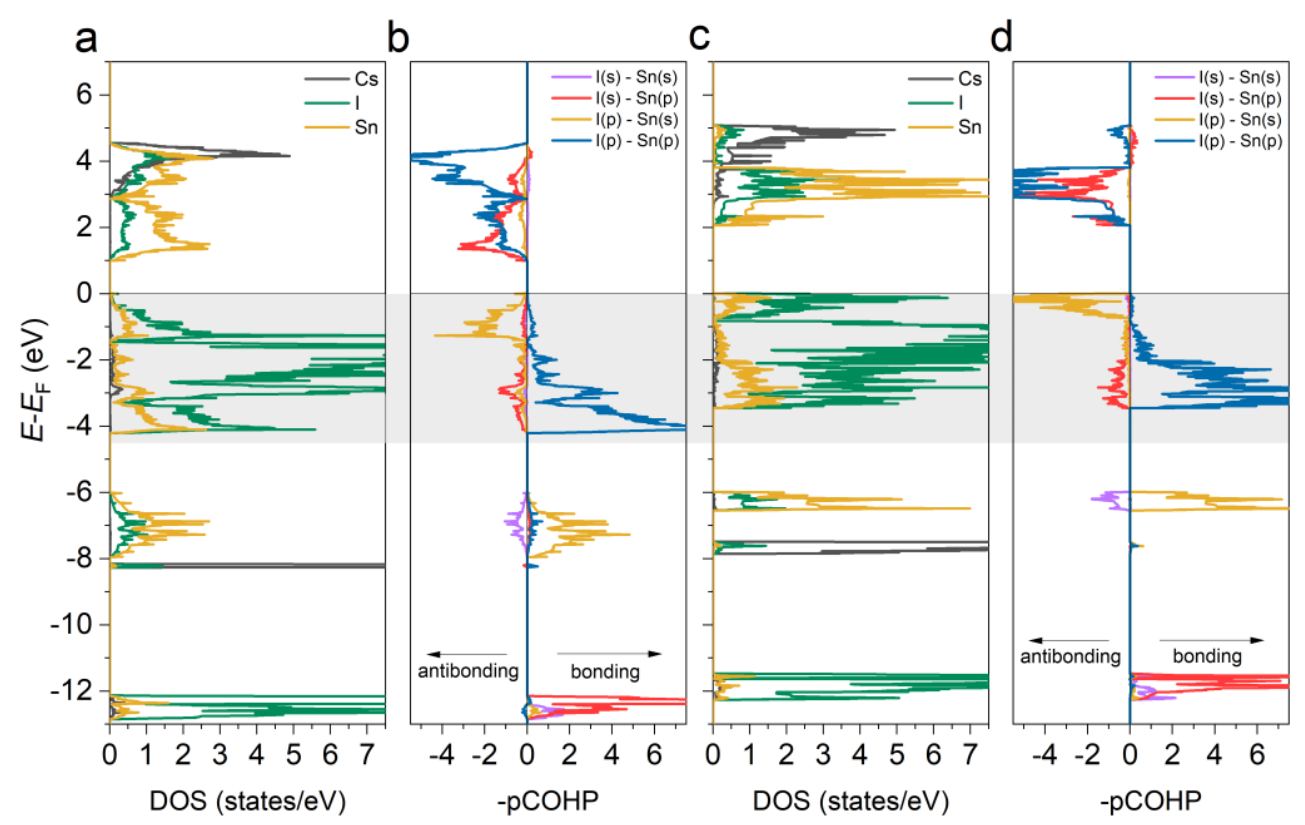

Figure S11. Comparison of partial Density of State (pDOS) and Crystal Orbital Hamilton Population analysis (-COHP) of $\mathrm{CsSnI}_{3}$ in the form of perovskite and non-perovskite: (a) and (c) are pDOS, and (b) and (d) are orbital-resolved -COHP. The -COHP plots are normalized by each $\mathrm{AMX}_{3}$ formula unit.

Table S5. The -ICOHP of metal-halide bond and FA-I interaction from $-4 \mathrm{eV}$ to $E_{\mathrm{F}}$ for the perovskite and non-perovskite $\mathrm{Cs}_{\mathrm{x}} \mathrm{FA}_{1-\mathrm{x}} \mathrm{PbI}_{3}(\mathrm{x}=0,0.25,0.5,0.75,1)$. The values are normalized by each $\mathrm{AMX}_{3}$ formula unit.

\begin{tabular}{|c|c|c|c|c|c|}
\hline $\mathrm{Cs}_{\mathrm{x}} \mathrm{FA}_{1-\mathrm{x}} \mathrm{PbI}_{3}$ & 0 & 0.25 & 0.5 & 0.75 & 1 \\
\hline -ICOHP perovskite I-Pb & 3.69 & 3.67 & 3.65 & 3.65 & 3.52 \\
\hline -ICOHP perovskite FA-I & 1.29 & 0.89 & 0.54 & 0.24 & 0 \\
\hline -ICOHP perovskite & 4.98 & 4.56 & 4.19 & 3.89 & 3.52 \\
\hline \multicolumn{7}{|l|}{} \\
\hline -ICOHP non-perovskite I-Pb & 3.35 & 3.34 & 3.53 & 3.49 & 3.50 \\
\hline -ICOHP non-perovskite FA-I & 1.32 & 0.87 & 0.56 & 0.27 & 0 \\
\hline -ICOHP non-perovskite & 4.67 & 4.21 & 4.09 & 3.76 & 3.50 \\
\hline & & & & \\
\hline -ICOHP difference & 0.31 & 0.35 & 0.1 & 0.13 & 0.02 \\
\hline
\end{tabular}


Table S6. The -ICOHP of metal-halide bond from $-4 \mathrm{eV}$ to $E_{\mathrm{F}}$ for the perovskite and non-perovskite $\operatorname{CsSn}\left(\mathrm{Br}_{\mathrm{z}} \mathrm{I}_{1-\mathrm{z}}\right)_{3}(\mathrm{z}=0,1 / 3,1 / 2,2 / 3,1)$. These values are normalized by each $\mathrm{AMX}_{3}$ formula unit.

\begin{tabular}{|c|c|c|c|c|c|}
\hline $\mathrm{CsSn}_{\left(\mathrm{Br}_{\mathrm{z}} \mathrm{I}_{1-\mathrm{z}}\right)_{3}}$ & 0 & $1 / 3$ & $1 / 2$ & $2 / 3$ & 1 \\
\hline -ICOHP $_{\text {perovskite } \mathrm{X}-\mathrm{Sn}}$ & 3.22 & 3.10 & 3.08 & 3.02 & 2.98 \\
\hline -ICOHP $_{\text {non-perovskite } \mathrm{X}-\mathrm{Sn}}$ & 3.17 & 2.34 & 2.34 & 2.32 & 2.30 \\
\hline -ICOHP difference X-Sn & 0.05 & 0.76 & 0.74 & 0.70 & 0.68 \\
\hline
\end{tabular}

Table S7. The -ICOHP of metal-halide bond from $-4 \mathrm{eV}$ to $E_{\mathrm{F}}$ for the perovskite and non-perovskite $\mathrm{CsSn}_{\mathrm{y}} \mathrm{Pb}_{1-\mathrm{y}} \mathrm{I}_{3}(\mathrm{y}=0,0.25,0.5,0.75,1)$. These values are normalized by each $\mathrm{AMX}_{3}$ formula unit.

\begin{tabular}{|c|c|c|c|c|c|}
\hline $\mathrm{CsSn}_{\mathrm{y}} \mathrm{Pb}_{1-\mathrm{y}} \mathrm{I}_{3}$ & 0 & 0.25 & 0.5 & 0.75 & 1 \\
\hline -ICOHP perovskite I-M $^{-\mathrm{I}}$ & 3.66 & 3.57 & 3.43 & 3.32 & 3.22 \\
\hline -ICOHP non-perovskite I-M $^{-}$ & 3.50 & 3.40 & 3.32 & 3.24 & 3.17 \\
\hline -ICOHP difference I-M & 0.16 & 0.17 & 0.11 & 0.08 & 0.05 \\
\hline
\end{tabular}

Table S8. Cell volume of $\mathrm{Cs}_{\mathrm{x}} \mathrm{FA}_{1-\mathrm{x}} \mathrm{PbI}_{3}, \mathrm{CsSn}_{\mathrm{y}} \mathrm{Pb}_{1-\mathrm{y}} \mathrm{I}_{3}$, and $\mathrm{CsSn}\left(\mathrm{Br}_{\mathrm{z}} \mathrm{I}_{1-\mathrm{z}}\right)_{3}$ for both phases of perovskite and non-perovskite. The unit is in $\AA^{3}$ and the values are normalized by each $\mathrm{AMX}_{3}$ formula unit.

\begin{tabular}{|c|c|c|c|c|c|c|}
\hline \multirow{2}{*}{ Phase } & \multicolumn{2}{|c|}{$\mathrm{Cs}_{\mathrm{x}} \mathrm{FA}_{1-\mathrm{PbI}} \mathrm{PbI}_{3}$} & \multicolumn{2}{c|}{$\mathrm{CsSn}\left(\mathrm{Br}_{\mathrm{z}} \mathrm{I}_{1-\mathrm{z}}\right)_{3}$} & \multicolumn{2}{c|}{$\mathrm{CsSn}_{\mathrm{y}} \mathrm{Pb}_{1-\mathrm{y}} \mathrm{I}_{3}$} \\
\cline { 2 - 7 } & perovskite & $\begin{array}{c}\text { non- } \\
\text { perovskite }\end{array}$ & perovskite & $\begin{array}{c}\text { non- } \\
\text { perovskite }\end{array}$ & perovskite & $\begin{array}{c}\text { non- } \\
\text { perovskite }\end{array}$ \\
\hline 0 & 260.44 & 255.64 & 224.96 & 214.25 & 233.09 & 218.97 \\
\hline $1 / 6$ & - & - & 219.46 & 208.56 & - & - \\
\hline $1 / 4$ & 247.62 & 247.42 & - & - & 230.80 & 217.40 \\
\hline $1 / 3$ & - & - & 213.54 & 202.46 & - & - \\
\hline $1 / 2$ & 242.86 & 247.75 & 206.81 & 197.66 & 228.65 & 216.36 \\
\hline $2 / 3$ & - & - & 200.76 & 190.94 & - & - \\
\hline $3 / 4$ & 238.95 & 229.79 & - & - & 226.93 & 215.05 \\
\hline $5 / 6$ & - & - & 194.45 & 183.79 & - & - \\
\hline 1 & 241.97 & 218.97 & 188.06 & 179.25 & 224.96 & 214.25 \\
\hline
\end{tabular}




\section{REFERENCES}

1. $\quad$ Liu, F.; Ding, C.; Zhang, Y.; Ripolles, T. S.; Kamisaka, T.; Toyoda, T.; Hayase, S.; Minemoto, T.; Yoshino, K.; Dai, S.; Yanagida, M.; Noguchi, H.; Shen, Q., Colloidal Synthesis of Air-Stable Alloyed $\mathrm{CsSn}_{1-\mathrm{x}} \mathrm{Pb}_{\mathrm{x}} \mathrm{I}_{3}$ Perovskite Nanocrystals for Use in Solar Cells. J Am Chem Soc 2017, 139 (46), 16708-16719.

2. $\quad$ Li, N.; Tao, S.; Chen, Y.; Niu, X.; Onwudinanti, C. K.; Hu, C.; Qiu, Z.; Xu, Z.; Zheng, G.; Wang, L.; Zhang, Y.; Li, L.; Liu, H.; Lun, Y.; Hong, J.; Wang, X.; Liu, Y.; Xie, H.; Gao, Y.; Bai, Y.; Yang, S.; Brocks, G.; Chen, Q.; Zhou, H., Cation and anion immobilization through chemical bonding enhancement with fluorides for stable halide perovskite solar cells. Nat Energy 2019, 4 (5), 408-415.

3. Zhumekenov, A. A.; Saidaminov, M. I.; Haque, M. A.; Alarousu, E.; Sarmah, S. P.; Murali, B.; Dursun, I.; Miao, X.-H.; Abdelhady, A. L.; Wu, T.; Mohammed, O. F.; Bakr, O. M., Formamidinium Lead Halide Perovskite Crystals with Unprecedented Long Carrier Dynamics and Diffusion Length. ACS Energy Lett. 2016, 1 (1), 32-37.

4. $\quad$ Prathapani, S.; Choudhary, D.; Mallick, S.; Bhargava, P.; Yella, A., Experimental evaluation of room temperature crystallization and phase evolution of hybrid perovskite materials. CrystEngComm 2017, 19 (27), 3834-3843.

5. Trots, D. M.; Myagkota, S. V., High-temperature structural evolution of caesium and rubidium triiodoplumbates. J. Phys. Chem. Solids 2008, 69 (10), 2520-2526.

6. Sutton, R. J.; Filip, M. R.; Haghighirad, A. A.; Sakai, N.; Wenger, B.; Giustino, F.; Snaith, H. J., Cubic or orthorhombic? Revealing the crystal structure of metastable black-phase $\mathrm{CsPbI}_{3}$ by theory and experiment. ACS Energy Letters 2018, 3 (8), 1787-1794.

7. Chung, I.; Song, J.-H.; Im, J.; Androulakis, J.; Malliakas, C. D.; Li, H.; Freeman, A. J.; Kenney, J. T.; Kanatzidis, M. G., CsSnI 3 : semiconductor or metal? High electrical conductivity and strong near-infrared photoluminescence from a single material. High hole mobility and phase-transitions. J Am Chem Soc 2012, $134(20), 8579-8587$.

8. Scaife, D. E.; Weller, P. F.; Fisher, W. G., Crystal preparation and properties of cesium tin(II) trihalides. J. Solid State Chem. 1974, 9 (3), 308-314.

9. Yi, C.; Luo, J.; Meloni, S.; Boziki, A.; Ashari-Astani, N.; Grätzel, C.; Zakeeruddin, S. M.; Röthlisberger, U.; Grätzel, M., Entropic stabilization of mixed A-cation ABX3 metal halide perovskites for high performance perovskite solar cells. Energ Eniviron Sci 2016, 9 (2), 656-662.

10. Li, Z.; Yang, M.; Park, J.-S.; Wei, S.-H.; Berry, J. J.; Zhu, K., Stabilizing Perovskite Structures by Tuning Tolerance Factor: Formation of Formamidinium and Cesium Lead Iodide Solid-State Alloys. Chem Mater 2015, 28 (1), 284-292. 